\title{
CIDADANIA E RETÓRICAS NEGRAS DE INCLUSÃO SOCIAL*
}

\author{
Antonio Sérgio Alfredo Guimarães
}

As sociedades modernas são herdeiras das revoluções dos séculos XVII, na Inglaterra, e XVIII, na França. Foram tais acontecimentos históricos que estabeleceram os padrões de sociabilidade e de civilização que se alastraram e ainda se alastram por todo o mundo pós-colonial, cujo pilar é o Estado de direito que protege indivíduos e cidadãos. T. H. Marshall (1977), em texto clássico, classificou a cidadania a partir dos direitos que a garantiam - civis, políticos e sociais -, e mostrou como eles foram conquistados progressivamente na Inglaterra. Em outros países, como ficou claro no debate das ideias seminais de Marshall (Turner, 1990; Carvalho, 2002), a história seguiu diversos outros cursos. Mas, se o desenvolvimento e conquista da cidadania não seguiram um padrão evolutivo ou uniforme em todos os Estados-nação, é incontestável que esses processos seguem em cada país uma certa periodização para a qual, para fins analíticos, a classificação sugerida por Marshall continua útil.

* Versão anterior deste texto foi lida no 2nd International Symposium of the Research Network for Latin America, Universidade de Cologne, 12-14 set. 2011. 
Para o caso das colônias europeias nas Américas, as revoluções modernas significaram, sobretudo, a formação de Estados independentes, como atestam a revolução norte-americana, no século XVIII, e as guerras de Independência das colônias espanholas e portuguesa, no século XIX. Tais Estados, entretanto, à diferença das metrópoles de que se separavam, não tinham a possibilidade de formarem-se como Estados-nação inclusivos para todos os seus habitantes, ou mesmo para todos os nativos de seus territórios. Ou seja, eram incapazes de estender o estatuto da cidadania moderna e o sentimento de pertencimento nacional, que lhe era atrelado, para todo o corpo social. A instituição da escravidão, assim como a reprodução de culturas e etnias variadas que serviam de base para a exploração de trabalho servil, impediram que se organizasse a unidade nacional e a igualdade de direitos. Mesmo o mais básico direito político - o voto -, no Brasil, foi restrito até recentemente - 1988 - por exigência 14 legal da alfabetização (ou seja, o acesso à cultura letrada) como pré-requisito para a participação eleitoral.

Na verdade, se, na Europa, o nascimento num determinado território e o compartilhamento de certos traços culturais, como uma língua comum, foram condições de primeira hora para a generalização da cidadania no interior dos Estados-nação; nas Américas, as etnias e, posteriormente, a racionalização e percepção das mesmas como raças, passaram a ser justificativas para garantir a negação desses direitos de cidadania e permitir a continuidade da escravidão ou do servilismo como modo de produção e como relação de trabalho. Aqui, como desenvolvi em outro texto (Guimarães, 2011), a solidariedade social, ou seja, a promessa aberta de integração racial e étnica pela via da aculturação, substituiu o ideal de igualdade social para as massas, uma vez abolida a escravidão e instituída a República como forma de governo.

O processo de construção da cidadania nos países americanos passa, pois, necessariamente por duas etapas: primei- 
ro, a abolição do escravidão; segundo, a construção de um sentimento nacional que inclua toda a sua população. Só assim os direitos civis, políticos e sociais podem ser generalizados para um corpo nacional, seja ele ou não multicultural.

Vou me limitar, neste artigo, apenas à segunda dessas etapas. Tomo o Brasil como exemplo do modo como a noção de raça impediu por muito tempo o desenvolvimento da cidadania nas nações americanas e como, de modo aparentemente paradoxal, a mesma noção está sendo capaz, nos dias de hoje, de acelerar tal desenvolvimento.

As classes sociais ${ }^{1}$ são fundamentais nas sociedades modernas porque nessas últimas já não existem os coletivos institucionalizados que monopolizam privilégios, como na Antiguidade ou na Idade Média. Nas sociedades modernas, toda e qualquer mobilização coletiva, fechamento de oportunidades ou monopolização de recursos, deve ser organizada por indivíduos que atuam livremente, como iguais, em mercados. As classes, enquanto coletivos, formam-se e desfazem-se a depender de conjunturas políticas, mas, enquanto estruturas, são permanentes, pois a organização de coletivos sociais é dada pela estrutura socioeconômica e pelo funcionamento dos mercados. Vistas como possibilidade de acesso ao mercado de bens e serviços, as classes atuam permanentemente, ao definir as chances individuais através da posse de capitais e de seus marcadores (Bourdieu, 1979). A propriedade de ativos financeiros e de imóveis, o domínio da norma culta da língua materna, de línguas universais, de códigos da cultura erudita, a posse do conhecimento cien-

\footnotetext{
1 Para uma importante tradição da sociologia não faz sentido falar de classes sociais antes da Idade Moderna. Weber, por exemplo, reserva o conceito para sociedades em que se formam mercados, ou seja, em que indivíduos interajam livremente. A tradição marxista, ao contrário, utiliza o termo para todas as épocas históricas, pois está interessada em explicar como se formam coletivos políticos a partir da teoria geral de que o plano fenomênico das relações sociais está determinado por fundamentos de estrutura econômica, ou seja, pela posição objetiva dos sujeitos numa determinada formação social. Ver Guimarães (2002).
} 
tífico e de credenciais escolares etc. constituem, pois, elementos permanentes de classificação social e de distinção a relativizar a equalização dos indivíduos em cidadãos.

Nas Américas, as classes sociais seguem historicamente um recorte muito próximo ao dos povos que aqui se encontram (e se mesclam) e que são referidos como raças. A mestiçagem pode confundir essas fronteiras ou acentuá-las. O decisivo para esse jogo classificatório é o modo como se constitui a cidadania, ou seja, a igualdade de direitos entre os indivíduos que compõem a nação. Como as hierarquias sociais se mantêm e se reproduzem no contexto ideológico republicano?

Seguirei aqui, de certo modo, as sugestões de Dumont (1960), desenvolvidas para o Brasil por DaMatta (1990), segundo as quais a manutenção de uma certa hierarquia social impediu que se desenvolvesse explicitamente entre nós uma rígida hierarquia racial. Ou seja, a subcidadania da maioria dos negros e mestiços evitou por muito tempo que 16 as raízes raciais da hierarquia social fossem visíveis.

Esclarecido o quadro teórico, passo a perseguir, no restante do texto, os desdobramentos da mobilização dos negros brasileiros em busca da ampliação de sua cidadania, através de diferentes períodos históricos, utilizando-se de elementos retóricos recorrentes. Começo por esboçar um quadro geral dessa mobilização a partir do final do século XIX, quando o fim da escravidão transformou a todos em cidadãos formais do Estado brasileiro.

\section{Um breve sumário da mobilização política dos negros depois da Abolição}

No período que sucedeu a campanha abolicionista, a mobilização política dos negros brasileiros teve continuidade com a formação da Guarda Negra por José do Patrocínio e sua defesa da monarquia contra o avanço do movimento republicano. $\mathrm{O}$ isabelismo, ou seja, o culto à princesa Isabel, que havia assinado a Lei Áurea em 13 de maio de 1888, 
organizou-se a par com a defesa da reforma agrária para os libertos, projeto de outro abolicionista monarquista negro, André Rebouças. Essa conjuntura do isabelismo, entretanto, foi curta. Ela foi marcada, sobretudo, pela atuação da Guarda Negra no Rio de Janeiro e outras cidades, que dispersava comícios republicanos (Gomes, 1999; Albuquerque, 2009). Em 15 de novembro do ano seguinte, em 1889, o imperador foi deposto por um golpe militar republicano, e a jovem República, aclamada pelas classes médias urbanas, os fazendeiros de café e toda a oligarquia agrária do país (Costa, 1985; Carvalho, 1987). Esvaíram-se, portanto, as oportunidades políticas para o isabelismo e para o monarquismo negro. No entanto, tal matriz de mobilização popular - o monarquismo e a justiça administrada por um soberano - sobreviveria como inspiração conservadora e moralista durante muito tempo, e, no meio negro, até os anos 1930, inspiraria alguns líderes e porta-vozes.

Os primeiros anos da República foram difíceis para o exercício da liberdade pelos ex-escravos e pelo povo em geral, principalmente no campo, onde as relações de trabalho se reacomodaram, não sem resistência, em novos arranjos de dependência e subalternidade (Garcia, 1986). Em alguns lugares, como em São Luís (MA), grupos populares reagiram contra a República dos oligarcas locais e a multidão foi dispersada a tiros, ao que se seguiu um período de repressão aos negros urbanos (Jesus, 2010). A Guerra de Canudos, entre 1896 e 1897, expôs ao país o isolamento e a desproteção das populações rurais (Cunha, 1902), e revoltas populares como a da Vacina (1904), a da Chibata (1910) foram reprimidas com banhos de sangue (Sevcenko, 1998; 2010). Sucederam-se inúmeros exemplos da radicalidade do estranhamento entre elites dirigentes e povo nesse período de estabilização da nova ordem republicana.

O primeiro exemplo de movimentação negra mais organizada, feita por dentro do sistema político, parece ter sido 
a campanha pela posse de Monteiro Lopes como deputado pelo Rio de Janeiro, em 1909, ele que já tinha sido eleito e não reconhecido pela Câmara (Abreu e Dantas, 2011; Dantas, 2010). Essa campanha mostrou os dois itens principais da agenda política negra nas décadas seguintes: o protesto contra o preconceito de cor e a luta pela inclusão social da população negra. $\mathrm{O}$ ativismo pelo reconhecimento da particularidade cultural negra seria saliente apenas mais tarde. Mas, naquele momento, alguns intelectuais negros e mulatos, como Manoel Querino, na Bahia, ou Astolfo Marques, no Maranhão ${ }^{2}$, recolhiam certos temas africanos e afro-brasileiros que engrossariam o caldo do que viria a ser compreendido, posteriormente, como concernente à cultura nacional.

Surgiu também, por essa época, a partir dos 1910, principalmente em São Paulo e Campinas, uma imprensa alternativa negra, à maneira dos jornais étnicos dos imigrantes europeus recém-chegados. Bastide (1983), ao analisar a 18 produção dessa imprensa, aponta para as suas principais funções sociais: de reconhecimento da classe média negra remediada; de dignificação social dos grandes homens negros brasileiros; e de protesto contra o preconceito de cor. Essa imprensa tinha o intuito de exercer liderança sobre as massas negras, organizando a solidariedade da comunidade negra em torno de ações educativas sob o signo de indisfarçável puritanismo.

À medida que se extremavam as posições políticas no Brasil a partir da crítica generalizada à democracia liberal, sub-repticiamente associada à República oligárquica, essa imprensa ressucitava as velhas categorias raciais, fazendo seu proselitismo em torno da arregimentação da raça negra. A República liberal foi acusada de ter barrado o processo mais radical de abolição da escravidão e deixado o povo

2 Sobre o primeiro, ver Nascimento e Gama (2009); sobre o segundo, Matheus Gato de Jesus (2011), neste dossiê. 
negro na situação deplorável em que se encontrava. Uma segunda abolição, portanto, era necessária. O núcleo dessa mobilização negra nos anos 1920 marcharia para a formação da Frente Negra Brasileira (1931-1937), sob a liderança patrinovista de Arlindo Veiga dos Santos ${ }^{3}$.

Mas, na Primeira República, houve ainda a radicalização ideológica entre fascistas e comunistas; o racismo reapareceu na cena política, agora em termos partidários e de Estado. Tal doutrina encontrou opositores também nos intelectuais nacionalistas, que recusavam a um só tempo o racismo e o comunismo, e que, embora simpatizantes de um Estado forte, estavam em busca de uma via democrática exclusivamente brasileira.

O golpe de Estado de 1930 e sua complementação em Estado Novo, em 1937, ambos presididos por Vargas, abortaram momentaneamente toda essa mobilização partidária racial para fundar um Estado autoritário e nacionalista, largamente regulador das relações sociais e econômicas, cujos objetivos foram estabelecer uma paz duradoura entre capital e trabalho, industrializar o país, desarmar os sertões e forjar uma cultura nacional homogênea a partir da diversidade étnica e cultural trazida pela imigração em massa e pelas heranças indígenas e africanas. Nesse contexto, as ideias em torno da democracia racial, enquanto sociabilidade autenticamente brasileira, tornaram-se consensuais entre todos os agrupamentos políticos e ideológicos, independentemente de clivagens étnicas ou raciais (Gomes, 1999; Guimarães, 2001; Guimarães e Macedo, 2008; Campos, 2005).

Duas qualificações, contudo, se fazem necessárias sobre esse último ponto. A primeira é que a desmoralização da política racial, provocada pelos crimes dos regimes fascistas, e a entronização da democracia racial como sociabilidade

\footnotetext{
3 Há muitas análises da Frente Negra Brasileira. Cito apenas alguns textos clássicos: Leite (1992), Fernandes (1965), Ferrara (1986) e Barbosa (1998).
} 
genuinamente brasileira não significou o fim da mobilização racial negra no Brasil, como se verá a seguir. A segunda é que o Estado Novo, assim como fizera a Primeira República, pouco alterou as relações sociais no campo, onde ainda vivia a maioria da população brasileira, e para a qual mesmo os direitos da cidadania regulada (Santos, 1979) continuariam ausentes.

A redemocratização de 1944 encontrou, pois, o país pronto para restabelecer a democracia parlamentar, sem necessidade de maiores reformas sociais ou econômicas. A propriedade rural continuou concentrada em poucas mãos, mas o banditismo foi eliminado. As antigas relações sociais transformar-se-iam muito lentamente, ao compasso do desenvolvimento regional diferenciado. Já no mundo urbano, os conflitos entre capital e trabalho encontraram nas leis sindicais, trabalhistas e previdenciárias uma estrutura duradoura. As formas de identidade racial que medraram 20 no solo da Segunda República tiveram que se conformar ao figurino mestiço do novo mito fundador da nação, ou seja, transformaram-se em protesto contra o preconceito de cor e de raça, e se justificaram perante a opinião pública enquanto aprimoramento da democracia racial; um esforço para fazê-la cada vez mais real. Ainda assim, no Rio e em São Paulo, organizações como o Teatro Experimental do Negro e intelectuais ativistas como Abdias do Nascimento, Solano Trindade, ou Guerreiro Ramos conseguiram alguma visibilidade.

É verdade, todavia, que, na Segunda República, os conflitos de classe e o anti-imperialismo fizeram das organizações estudantis e sindicais urbanas e rurais entidades quase-monopolizadoras da luta social, e o debate em torno do desenvolvimento social galvanizou os intelectuais mais proeminentes do período. É como se o problema racial no Brasil estivesse definitivamente resolvido. Na agenda política da esquerda, a luta pela segunda abolição foi subsumida pela luta pelo socialismo. 
Foi outro golpe militar, o de 1964, seguido da radicalização do regime em 1968, que fraturou definitivamente tal agenda de esquerda: introduziu a política étnico-cultural e reabriu a discussão sobre a democracia. O regime militar descambou rapidamente da repressão política por processos judiciais e encarceramento, para formas mais violentas e totalitárias de persuasão, através do uso da tortura e da eliminação física de opositores. A oposição política civil, em reação, radicalizou e aprimorou o pensamento sobre os direitos civis e humanos nas democracias modernas. A crítica ao autoritarismo de Estado acabou também por iluminar as hierarquias sub-repitícias sobre as quais vicejava o poder nas relações sociais brasileiras: as hierarquias de classe, de raça, de gênero, entre outras. Ao mesmo tempo, sob o abrigo do Estado autoritário e de sua política internacional de aproximação com a África, puderam se estabelecer grupos culturais negros em busca de suas raízes e de seus próprios mitos (Santos, 2005). A partir daí, a democracia racial começou a ser denunciada, nos meio negros, como farsa.

Mas a recusa completa da democracia racial não ocorreu repentinamente; muitas tentativas ainda foram feitas, depois que Florestan (Fernandes, 1965) a caracterizou como um mito, e que Abdias (Nascimento, 1968) a chamou de logro, em 1968, para explorar o terreno de possibilidades de luta e de resistência, demarcado pelo mito e sua recusa do racismo. Até meados dos anos 1980, enquanto as organizações negras conviviam com o regime autoritário, as ambiguidades do mito, a um só tempo falso e verdadeiro, o tudo que é nada, no dizer do poeta, foram exploradas como bandeira de luta, no mote "por uma autêntica democracia racial" (MNU, 1982). Do mesmo modo, coerentemente, o movimento negro que ressurgiu nos anos 1970 reorganizou-se como Movimento Negro Unificado Contra a Discriminação Racial.

Foi preciso instalar a Terceira República, em 1985, e promulgar a Constituição, em 1988, para que o movimen- 
to negro renegasse completamente o ideal de democracia racial; adotou, em contrapartida, uma agenda radical de defesa dos direitos humanos e dos direitos civis e sociais dos negros. Iniciou-se, então, uma fase de denúncia radical da precariedade dos direitos dos cidadãos negros, através da criação de múltiplas ONGs voltadas para a advocacia de direitos individuais, como os serviços de SOS Racismo, e a formação de organizações populares que passaram a agir em torno de atividades de cultura, educação, emprego e saúde. Essa é a fase que tem como pressuposto a ruptura ideológica com os ideais da democracia racial e, como meta, a afirmação radical da igualdade racial. Não por acaso tal movimento conduziu à demanda por ações afirmativas nas áreas de emprego, educação e saúde. A simples igualdade de tratamento, inscrita na ordem democrática anterior, deixava de ser satisfatória. O movimento negro passou a ter como meta o desmantelamento das desigualdades raciais 22 através de políticas públicas de discriminação positiva.

Que tal mudança de estratégia e de objetivos fosse condizente com o momento histórico e com a radicalização democrática trazida pela Carta de 1988 ficou claro com a progressiva aceitação de tal agenda pelo conjunto da sociedade brasileira. Foi o que se passou, por exemplo, com a educação superior brasileira, que vivia então uma crise de crescimento tanto no setor público, pela estagnação de recursos e de vagas, quanto pelo setor privado, por conta da grande inadimplência e evasão de estudantes. Entre 2002 e 2011, cerca de $70 \%$ das universidades estaduais ou federais adotaram alguma forma de ação afirmativa para a seleção de estudantes, enquanto no setor privado o governo federal instituiu o Prouni, um amplo programa de bolsas para estudantes negros e carentes.

Para compreender a extensão desse desdobramento do movimento no tempo, partindo de estratégias de ação nitidamente caudatárias de ideologias de embranquecimento 
e finalizando com estratégias radicalmente igualitaristas, é necessário mergulhar, ainda que também rapidamente, na análise das ideologias que vingaram nos meios sociais negros.

Começo pelas ideologias raciais.

\section{Ideologias raciais}

No Brasil, como em outras partes das Américas, o processo de Abolição propiciou uma onda de reflexão erudita, pseudocientífica, em torno do conceito de raça, cujo resultado foi criar justificativas para a continuada desigualdade social entre europeus e não europeus. Os primeiros reivindicavam para si a igualdade cidadã e os direitos políticos, enquanto aos segundos ficavam reservadas as posições subalternas. Como bem observou Dumont (1960), as sociedades modernas americanas elegeram o racismo como justificativa natural para a hierarquia social que permaneceria nas repúblicas liberais.

Diferentemente do que se passou nos Estados Unidos, no entanto, a raça no Brasil não criou para os indivíduos, principalmente os mestiços, obstáculos intransponíveis. Várias explicações foram dadas para tal diferença, que não cabe aqui resenhar. O fato é que a noção mais antiga de "cor", em torno da qual, na Europa, desde a Antiguidade, se diferenciaram povos e indivíduos, continuou a ter mais importância que as explicações pseudocientíficas baseadas em raça. Ainda que as classificações de cor tivessem sofrido uma espécie de releitura racista erudita e permanecessem doravante com tal substrato, não se desenvolveu no Brasil nem uma classificação racial bipolar, nem emergiram regras classificatórias precisas (Harris, 1956). As circunstâncias e situações sociais permitiriam a manipulação das classificações de cor (Azevedo, 1963).

Tal desenvolvimento estava em homologia com a impossibilidade demográfica e política de se criar uma nação totalmente branca, pelo que quero dizer uma nação apenas com descendentes de europeus não miscigenados e recém-imigrados. A impossibilidade demográfica estava na baixa 
atratividade do Brasil para as correntes imigratórias europeias do final do século XIX e começo do XX; a impossibilidade política residia na centralidade social e econômica que ganhou parte da população brasileira de origem mestiça, que se autodeclarava branca.

Aqui, talvez valha a pena traçar, ainda que em traços rápidos, as diferenças dos sistemas de classificação racial vigentes nos Estados Unidos, na Europa e no Brasil, de modo a evitar mal-entendidos e excesso de polissemia. $\mathrm{O}$ sistema norte-americano utiliza a regra de hipodescendência, ou seja, descendência traçada a partir do cônjuge inferiorizado socialmente, para traçar os limites dos grupos raciais, que são referidos abertamente como raças. $\mathrm{O}$ sistema europeu contemporâneo, desde o fim da Segunda Guerra, rechaça o termo raça e classifica os indivíduos, seja em termos culturais, etnias propriamente ditas, ou a partir da cor da pele, sem referência a descendência biológica. $\mathrm{O}$ 24 sistema brasileiro também recusava o termo raça até recentemente, preferindo o de cor, e também não tem uma regra clara de classificação por descendência, mas utiliza outras marcas corporais, tais como cabelo, formato do nariz e dos lábios, para classificar os indivíduos em grupos. Se o termo raça era tabu até há pouco, hoje em dia usa-se correntemente o par "raça/cor" em recenseamentos e pesquisas de opinião, assim como no dia a dia se os utiliza como termos intercambiáveis. Pode-se, portanto, dizer, grosso modo, que o sistema estadunidense é o mais fechado de todos, posto que delimita com precisão os grupos de descendência; o sistema europeu é um pouco mais aberto, posto que o critério único de cor da pele permite maior trânsito entre os grupos, ainda que a categoria de pele "escura" possa dar origem a uma espécie de purgatório racial; finalmente, pode-se dizer que o sistema brasileiro, utilizando uma pluralidade de marcas físicas, possibilita a formação de vários grupos raciais entre o branco e o negro. 
Esse é o sistema que pode tratar a mistura racial como processo, pois é o único que tem os elementos para demarcar as etapas de tal transformação. De fato, a jovem nação republicana adotaria, no auge da moda intelectual do racismo, o discurso do branqueamento gradual de toda a sua população, promovendo a imigração e aceitando a mestiçagem como algo necessário e virtuoso (Skidmore, 1974; Ventura, 1991; Schwarcz, 1993). Mas a crença no branqueamento era apenas uma das possibilidades abertas pela matriz ideológica que conformou o nascimento da jovem nação sul-americana. Essa matriz é enunciada pela primeira vez, de modo erudito, no Segundo Império, por Karl Frederick Von Martius, em ensaio de 1845 para o Instituto Histórico e Geográfico Brasileiro. Von Martius chama a atenção para o fato de que a história do Brasil deveria ser escrita levando em consideração que seu povo seria formado pela mistura de três raças - "a cor de cobre ou americana, a branca ou caucasiana, a preta ou etiópica” (Von Martius, [1845] 1956, p. 42).

Três variantes possíveis dessa matriz conheceram desdobramentos importantes para a formação racial negra no Brasil: o embranquecimento, o mulatismo e a negritude.

O embraquecimento da população brasileira surge como corolário da superioridade da raça branca e da civilização europeia, mas como negação das teorias racistas que teorizavam a mestiçagem como degenerescência. Constitui-se, portanto, no primeiro vértice da matriz enunciado por Von Martius, ao pregar que não apenas o povo conquistador imporia a sua língua e a sua civilização, mas também os seus atributos e qualidades raciais sobre os povos colonizados. Talvez a versão mais bem-acabada dessa versão otimista do embranquecimento esteja na tese apresentada por João Baptista Lacerda (1911) ao Congresso da Universal das Raças, em Londres, em 1911. Segundo essa formulação, a raça negra seria absorvida paulatinamente através da miscigenação, gerando um estoque de mulatos eugênicos, assim 
como, por fim, através de sucessivos intercruzamentos, esses últimos também acabariam por ser incorporados ao grupo branco. É importante notar, entretanto, algumas outras versões da mesma tese: uma mais pessimista - que entendia ser necessária a substituição da raça negra, via intensificação da emigração europeia, expulsão dos africanos libertos e maior mortalidade natural da raça negra - e outra mais otimista - que encarava o embranquecimento como um processo mais geral, que compreendia não apenas miscigenação, mas também a aculturação e assimilação social de negros e indígenas à cultura luso-brasileira. Em suas três variantes, o embranquecimento é uma ideologia de longa duração, e que limita os avanços da cidadania no Brasil.

A segunda variante surge como um desdobramento mais radical e mais afinado com a proposta racialista de von Martius, segundo a qual da mestiçagem entre indígenas, brancos e negros formava-se no Brasil uma metarraça. A 26 construção do imaginário de uma nação mestiça, que incluiria a totalidade dos indivíduos livres, foi intensificada pelo movimento abolicionista, e se aprofundou durante o período republicano. Essa formulação talvez se constitua no veio mais refinado do pensamento social brasileiro, que encontra seus expoentes, em termos de enunciação, em Joaquim Nabuco e Gilberto Freyre. Segundo esse pensamento, a liberdade, conquistada pela abolição da escravidão, transmuta-se imediatamente em cidadania, na ausência de preconceitos de raça. As desigualdades sociais remanescentes passam a se ancorar na ordem econômica e cultural das classes sociais. Cabe ao Estado incorporar e regular através de políticas sociais o acesso dos cidadãos ao pleno gozo de seus direitos, e promover desse modo a justiça, a educação, a saúde e a seguridade social de todos. O Estado é o único ente civilizador e promotor da harmonia social (Vianna e Carvalho, 2000). Não há lugar, nesse pensamento, para a teoria de Marshall do desenvolvimento da cidadania pela conquistas de direitos. 
Essa variante da matriz vonmartiana seria chamada por alguns intelectuais de mulatismo, ou seja, de uma forma de conceber a nação brasileira segundo a qual o mulato seria o brasileiro típico, mais que o branco oriundo da emigração europeia ou de sua mistura com os descendentes de portugueses. Como se pode imaginar, a acusação de mulatismo provém daqueles que acreditam no papel de liderança que a cultura europeia (e não a afro-indo-luso-brasileira) deve exercer sobre a nação brasileira. Esse tipo de caracterização do mulatismo esteve presente entre muitos intelectuais paulistas dos anos 1930 e 1940 (Duarte, 1947; Bastide, 1961).

Enfim, a terceira variante é a negritude brasileira (Bastide, 1961). Apesar de muito influente no meio negro, e talvez pour cause, tal variante não encontrou grande apelo nos meios intelectuais, ficando quase que restrita ao enunciado de Guerreiro Ramos (1957). A negritude, como bem caracterizou Bastide, consiste numa radicalização do mulatismo, ao enxergar como negros todos os afrodescendentes e propor que, no Brasil, o povo é negro; ou seja, segundo tal enunciado, não faz sentido pensar o negro enquanto etnia separada, posto que ele é o esteio demográfico da nacionalidade. Por seu turno, a designação do povo como negro, e não mulato ou mestiço, consiste propositadamente na busca de valorizar o elemento mais estigmatizado da formação nacional, revertendo a visão colonialista europeia, introjetada pelas elites nacionais, do Brasil enquanto país branco e de sua cultura como prolongamento da portuguesa.

São essas três vertentes - o embranquecimento, o mulatismo e a negritude - que delimitam o espaço ideológico-racial em que vicejam algumas estratégias discursivas negras para a luta pela ampliação da cidadania.

\section{Retóricas negras e a recorrência de seus temas discursivos}

Quatro retóricas de inclusão podem ser distinguidas nesse longo período de mobilização negra. A primeira delas foi 
caracterizada por Bastide (1983, p. 150) como puritanismo. Trata-se do discurso sobre a moral - comportamentos, atitudes e valores - adequada à convivência numa sociedade burguesa. Bastide disse ter preferido chamá-lo assim "porque a moralidade é essencialmente subjetiva, ao passo que o puritanismo dá atenção antes de mais nada ao que se vê, às manifestações exteriores e que podem classificar um ser no interior de um grupo". Trata-se, no entanto, propriamente de um discurso sobre a moral adequada à integração social dos negros nas classes médias urbanas. Numa sociedade em que não era legalmente permitida a discriminação com base na raça ou na cor, a situação de inferioridade e de subalternidade social do negro não poderia ser regulada apenas através dela; muito ao contrário, quando tal discriminação ocorresse, teria que ser discreta e de preferência passível de ser atribuída à operação de mecanismos de classificação social. Eram, portanto, através dos mecanismos 28 de formação e de reprodução das classes - a escolaridade formal, as boas maneiras, a moral, a religião, o domínio da língua culta etc. - que as discriminações sociais poderiam ser mais eficientemente exercidas e, mais que isso, que os negros poderiam se reproduzir espontaneamente enquanto classe. Está aí a sabedoria da imprensa negra de então em alcunhar a população negra de "classe dos homens de cor" antes de adotar a designação de "raça negra".

O puritanismo, portanto, foi a primeira tentativa, depois do abolicionismo, ou seja, depois da conquista da cidadania formal, de ampliar os direitos efetivos do povo negro através de uma forma comunitária de solidariedade: a racial, que, como vimos, desloca-se paulatinamente da cor para a raça, à medida que avançam no Brasil as ideologias políticas racistas, como o fascismo. Engana-se, pois, quem enxerga no puritanismo uma simples introjeção da ideologia do embranquecimento entre a classe média negra. A recusa do pan-africanismo e das práticas culturais afro-brasileiras que medram nos 
meios populares negros devem ser lidas como enquadramento à lógica de identificação e de reprodução das classes, como negação e tentativa de desconstrução do habitus de classe das camadas populares. É claro, porém, que um dos pressupostos do puritanismo é a prevalência das ideias sobre a inferioridade das práticas culturais africanas e de suas ramificações brasileiras. No entanto, quero chamar a atenção para o fato de que os códigos da alta cultura europeia - sejam maneira de vestir, falar ou se comportar - permanecem como marcadores de distinção das classes altas mesmo quando a chamada "cultura negra" passa a ser aceita em sua plenitude.

O puritanismo é uma estratégia de elevação de status social de um grupo através da formação de uma comunidade racial ou seja, de uma origem de raça comum - através do exercício da solidariedade e da liderança. Alguns dos temas discursivos (que os sociólogos norte-americanos chamam de frames) que aparecem na retórica do puritanismo foram emprestados ao movimento abolicionista e iriam reaparecer em todas as mobilizações negras do século XX: o papel colonizador do negro no Brasil, o negro como criador da riqueza nacional, o talento do mulato, o mestiço como o tipo mais brasileiro (somos todos mestiços, até mesmo os portugueses), a abolição como abandono e desproteção, a ausência do preconceito de raça no Brasil, mas a continuidade do preconceito de cor.

No tempo em que o puritanismo da Frente Negra Brasileira atingia seu ápice, em 1937, já era, entretanto, um discurso embolorado. Isso porque, desde os anos 1920, os modernistas brasileiros buscavam inspiração para o seu vanguardismo na cultura popular negra e mestiça, buscando ali a alma do Brasil. Os festejos populares, as danças, o folclore, todas essas manifestações serviam de referência para a construção de uma nova estética de autenticidade, surgida na cola dos movimentos artísticos europeus, que, do dadaísmo ao surrealismo, descobriram a arte primitiva, africana e oriental. Tal descoberta, no Brasil, caminhou passo a passo com o estudo dos africanismos 
pela antropologia cultural (Ramos, 1937; Herskotivs, 1943), principalmente dos candomblés jêjes-nagôs, que transformam a Bahia, primeiro em laboratório, depois numa espécie de Roma negra (Lima, 1964), local de origem espiritual para reconstrução das tradições africanas no Brasil.

Toda a força do renascimento artístico e espiritual modernista teve enormes consequências para os discursos reivindicatórios negros: nuançou seu projeto de classe, assentado em marcadores de status pequeno-burgueses e europeus, àquela altura (anos 1920 e 1930) já sob à crítica de inautenticidade das vanguardas artísticas e intelectuais. Dois outros temas seriam acrescentados, portanto, nos anos 1940, à retórica negra: o povo, no Brasil, é negro; e a cor, simples aparência. Eles seriam acionados, principalmente, no discurso da democracia racial, que passaria a dominar a política cultural e ideológica do Estado Novo.

Já escrevi em outras ocasiões sobre a democracia racial 30 (Guimarães, 2001; Guimarães e Macedo, 2008), mas é preciso aqui, sinteticamente, retomar as suas origens e especificar a sua vertente negra. As origens das ideias consteladas ali têm fontes diversas, algumas eruditas, outras populares, reunidas sob a motivação política mais profunda que a animou. A fonte erudita pode ser encontrada na inspiração hispanista (Diaz Quiñones, 2006), que tomou conta dos intelectuais latino-americanos no começo do século XX, à procura da especificidade da civilização ibérica, seja em termos dos seus contatos com outros povos, seja da sua forma de governar, seja da sua cultura. A fonte popular vem da campanha abolicionista, que desemboca num movimento social de certa pujança ao ganhar as ruas (Alonso, 2010) mas que teria sua maior legitimação intelectual nos escritos de Castro Alves, Rui Barbosa e Joaquim Nabuco. A fonte política pode ser encontrada em vários intelectuais, alguns de corte mais racialista, como Cassiano Ricardo (Campos, 2005), outros mais culturalista, como Arthur Ramos ou Gilberto Freyre. 
Já se encontrou, em Oliveira Lima (1911), o argumento, mais tarde retomado por Gilberto Freyre $(1933,1936)^{4}$, de que no Brasil colônia a aristocracia portuguesa era muito mais aberta ao contato com as classes populares, incorporando com frequência não só bastardos, mas pardos de talento, "não constituindo o sangue negro um obstáculo insuperável nem sequer à mercês e graças régias" (Oliveira Lima, 1922, p. 32). Essa democracia de que fala Oliveira Lima, ou seja, a falta de rigidez nas classificações de classes ou de raças, seria alçada por Freyre à singularidade da colonização portuguesa, embrião de uma democracia social e étnica, mais profunda e humana que a democracia liberal anglo-saxônica ou francesa, posto que permitiria a incorporação e a mobilidade social de diversas raças nas novas nações oriundas da expansão europeia. Tal singularidade da democracia na América portuguesa seria chamada também de democracia racial por outros, como Cassiano Ricardo; no entanto, nesse como em outros autores, a concepção de uma democracia autoritária, baseada numa clara hierarquia sob o comando europeu ou branco é mantida intacta, tal como fora anunciada em 1845 por Von Martius.

A simpatia despertada por Casa-grande $\mathcal{E}$ senzala está justamente em que, nele, a hierarquia racial cede lugar ao que Benzaquém Araújo (1994) chamou de equilíbrio dos contrários. Ou seja, são as relações de poder entre senhores e escravos, homens e mulheres, adultos e crianças, que determinam a hierarquia social e não as raças. Gilberto Freyre encontraria espaço para incorporar inteiramente a variante popular da democracia racial, ou seja, aquela em que o negro e o mulato eugênico passam a ser matriz da futura nação. Nessa leitura popular, a que Freyre empresta o encanto de sua prosa, a mestiçagem submerge a hierarquia, deixando-a transparecer tão somente em certas preferências estéticas ou culturais.

4 A influência de Oliveira Lima sobre Freyre foi analisada por Gomes (2001). 
Tal democracia racial seria aquela autenticamente brasileira, para a qual se requereria um Estado forte e regulador das relações sociais, de modo que os potentados privados não sucumbissem à tentação de transformar diferenças raciais $\mathrm{e}$ culturais em hierarquias sólidas. Apenas as diferenças de classe poderiam a ser reconhecidas pelo Estado e por ele mediadas, e reguladas por extensa legislação. Contra a petrificação da diversidade racial e de classe o Estado deveria agir de modo soberano, por cima dos cidadãos. Foi esse ideal de democracia, cujo cerne não se encontra nos direitos individuais, mas na inexistência de barreiras de cor à mobilidade social dos indivíduos, e cuja legitimidade é retirada não da utopia do indivíduo livre, portador de direitos, mas da inexistência de coletivos cujas características adscritas lhes garantam privilégios, que atendia também aos anseios populares e negros, aqueles que mantinham a bandeira da segunda abolição.

Assim, paradoxalmente, a hierarquia racial defendi32 da pelas elites brasileiras, abertamente, como racismo, ou sob a forma mais branda de nação mestiça liderada pela herança cultural branca ou europeia, não desaparece, mas é submergida por uma ordem regulada de classes sociais. Nessa nova hierarquia, como não podia deixar de ser, se insinuam como preferências as marcas físicas, raciais e culturais das classes dominantes. O negro eugênico se transforma em moreno, a beleza em graça divina. O conflito racial transmuda-se em conflito social. Para exemplificar com uma canção muito popular de Adelino Moreira, de 1959, o sonho de amor impossível de um negro por uma branca é assim lamentado: "Não devia [sonhar] e por isso me condeno/ Sendo do morro e moreno/ Amar a deusa do asfalto". Ninguém sabe ao certo de que cor eram realmente amante e amada, mas se conhece sim que o triste enlace resvala em "negra solidão". O conflito se desloca, como se vê, para outra hierarquia. De mesmo modo, no cancioneiro da época, a cabrocha, a morena e a mulata passam a ser as figuras 
femininas mais exaltadas. Do mesmo modo, a Bahia, que fora retratada por Von Martius como a mais portuguesa das cidades brasileiras ${ }^{5}$, e que fora caracterizada como a "mulata velha” na Primeira República ${ }^{6}$, passa a ser associada, a partir do Estado Novo, à mística afro-brasileira, como terra da magia e do feitiço, cantada nos sambas de exaltação, junto com o Rio de Janeiro e os morros cariocas.

Para os intelectuais negros que abraçam o ideal da democracia racial, contudo, é importante frisar que o fazem, como vimos, ao ressignificar o movimento da negritude e substituir o pan-africanismo pelo nacionalismo anticolonialista. A polissemia de termos como democracia racial, negritude e cultura afro-brasileira tem que ser ressaltada. Para os negros, a primeira expressão significava a sua integração numa ordem social sem barreiras raciais; a segunda era uma forma de patriotismo que acentuava a cor negra do povo brasileiro; enquanto a terceira realçava a cultura sincretizada e híbrida do Brasil (Bastide, 1976).

Para chegar aos nossos dias - quando a Bahia é caracterizada, abertamente, como cidade negra, o termo raça é introduzido nos censos demográficos, e o multiculturalismo e o igualitarismo racial são doutrinas dominantes nas organizações políticas e culturais negras -, é preciso compreender como certos signos de identidade étnica foram apropriados pelas elites negras e como os direitos do cidadão passaram a ser centrais na definição da democracia.

Roger Bastide, que já disponibilizou a chave para a compreensão do puritanismo negro e da negritude brasileira, pode oferecer ainda outra para entender o surgimento da identidade étnica nos anos 1970.

\footnotetext{
5 Rodrigues observa, ao comentar a Viagem ao Brasil, de Von Martius, que a Bahia era a província brasileira em que se podia notar "um maior apego à Portugal e à conservação das leis e às praxes portuguesas". Von Martius notava também "a expedita atividade comercial do baiano, prático, sólido" (Von Martius, [1845] 1956, p. 437).

6 Ver a nota 66 de Guimarães (1999).
} 
Segundo ele, o avanço das religiões afro-brasileiras no sul e sudeste do país, a descolonização da África e a consequente emergência de uma elite negra africana de circulação internacional, assim como o crescimento e autonomização de uma classe média mulata não incorporada às elites como socialmente branca, fazem com que a negritude brasileira deixe de referir-se apenas aos aspectos físicos-raciais dos negros para ressaltar a sua autenticidade e singularidade cultural enquanto afro-brasileiros ${ }^{7}$.

Para Bastide, as bases sociais para a aceitação e adaptação de teorias que circulariam internacionalmente com maior intensidade nas décadas seguintes, como o multiculturalismo e multirracialismo, teriam sido assentadas no Brasil pelo "milagre econômico", como ficou conhecido o grande desenvolvimento econômico e social brasileiro dos anos 1970 .

Da mesma época, acrescento, data também a grande guinada da intelectualidade política brasileira - à esquerda 34 e à direita -, que recusou a antiga aspiração por uma democracia autenticamente local e voltou-se para a crítica da insuficiência histórica das garantias aos direitos humanos e do cidadão. Abriu-se, então, caminho para que as desigualdades raciais no país pudessem ser denunciadas como genocídio do povo negro, ecoando a celebre petição apresentada por Paul Robeson e William L. Patterson (1970) à Assembleia Geral da ONU em 1951. Quem soltou o grito foi Abdias do Nascimento (1978), que liderou o movimento por democracia racial e pela negritude nos anos 1940 .

Nada mais compreensível que qualquer tentativa de restringir a democracia a qualquer um de seus aspectos fosse recusada. A ditadura militar foi instalada no país desde 1964,

\footnotetext{
7 'Ela não pode aceitar a 'negritude' do ponto de vista puramente físico; essa negritude não pode ser senão cultural. E eu acrescento: o que define e produz os dois movimentos, de incorporação nacional e de autenticidade, coerentes entre eles, não é senão aquele de uma identidade cultural 'africana', mais que de uma identidade resolutamente 'afro-brasileira'” (Bastide, 1976, p. 27).
} 
camuflada sob a aparência de democracia representativa, mantendo o Legislativo e Judiciário como poderes autônomos, refazendo o sistema político partidário e a Constituição, intervindo e limitando tais poderes de maneira ad hoc. A ditadura seguiu, assim, uma longa tradição autoritária, que já rendera frutos na Primeira e Segunda Repúblicas, e servira de inspiração a Vargas, instituindo na presidência uma espécie de poder moderador imperial. Na luta pela redemocratização do país, portanto, as oposições se viram obrigadas a radicalizar a sua concepção de democracia (Weffort, 1992): fizeram a crítica histórica da sociedade e da política brasileiras, repudiaram qualquer espécie de excepcionalismo ou singularidade nesta matéria, e propugnaram por uma defesa radical das liberdades civis e dos direitos do indivíduo e do ser humano.

$\mathrm{O}$ igualitarismo negro, portanto, foi resultado de um amadurecimento de demandas congruentes: abandonou-se a bandeira de luta "por uma autêntica democracia racial" (MNU, 1982) e adotaram-se demandas por reconhecimento de sua particularidade cultural e por ações afirmativas que estabelecessem maior paridade de oportunidades entre brancos e negros.

\section{A cidadania dos negros}

Para concluir esse artigo, vou sumarizar brevemente meus argumentos, explicitando alguns fios condutores e uma periodização que ficaram implícitos. Vianna e Carvalho (2000), em artigo seminal, retomaram uma tese cara a Oliveira Vianna (1959), para insistir no papel central que desempenhou o Estado no processo civilizatório brasileiro, avançando e garantindo direitos e liberdades contra a oposição das classes dominantes, e com o apoio difuso ou amorfo das massas e das classes dominadas. Foi assim na Abolição, foi assim no Estado Novo. José Murilo de Carvalho (2002), em sua história da cidadania no Brasil, demonstrou como tal protagonismo do Estado fez com que os direitos 
sociais fossem garantidos para as camadas urbanas, antes mesmo que as liberdades políticas e civis estivessem plenamente desenvolvidas. Esse processo Wanderley Guilherme dos Santos (1979) havia chamado de "cidadania regulada".

Como procurei expor acima, ainda que rapidamente, foram três momentos de ruptura com a ordem racial estabelecida, às vezes com o protagonismo maior do Estado, mas com mobilização social maior nas últimas décadas, em que os negros brasileiros viram respeitados os seus direitos à cidadania.

Sem dúvida, o momento inicial foi a conquista da liberdade individual, pois com o fim da escravatura generalizou-se definitivamente a disjunção entre ser negro e a restrição à liberdade individual. Mas a liberdade assim conquistada não se traduziu, como vimos, em cidadania política ativa; apenas deslanchou o processo de construção nacional, em que tais indivíduos eram mais assujeitados (Garcia, 36 1986) que sujeitos. A Primeira República representou bem essa época em que competiram duas lógicas de cidadania: de um lado, a onda civilizadora republicana, limitada às classes altas e remediadas, que, do ponto de vista cultural, significava a europeização do Brasil (Freyre, 1936) e a consequente negação da herança africana. No movimento descendente vieram o racismo pseudocientífico e a tentação de embranquecer a nação, assim com a resposta negra pequeno-burguesa, que, em busca de inclusão social e respeitabilidade, arrebentou-se no puritanismo negro. De outro lado, no movimento ascendente, ocorreu nos meios intelectuais e artísticos a valorização das manifestações populares, das artes primitivas, do folclore, e das heranças culturais africanas. A arrebentação dessa onda foi múltipla: o modernismo, o ideal da nação mestiça, a retórica afro-brasileira. $\mathrm{O}$ que antes era visto como africano e estrangeiro passou a ser tematizado como afro-brasileiro ou simplesmente brasileiro. Ao invés de aceitar as diferenças e propor a igualdade 
entre as heranças, optava-se pela hibridez e a convivência e tolerância das desigualdades.

O período seguinte começou já na Revolução de 1930 e seguiu pelo Estado Novo. À conquista do reconhecimento do legado cultural da raça negra, juntaram-se os direitos sociais do trabalhador urbano. Forjaram-se, nesse período, compromissos políticos e culturais que seriam expressos no ideal de democracia racial: cidadania regulada, nacionalização das culturas étnicas e raciais, recusa ao racismo. Mas a Segunda República, apesar de restituir as liberdades políticas, não as generalizou ou aprofundou. O trabalho no mundo rural, nas grandes propriedades, continuou a ser regido por formas de sujeição pessoal e de violência herdeiras do escravismo (Garcia, 1986). Do ponto de vista dos negros, qualquer avanço em termos de direitos políticos ou sociais se fez apenas nas lutas de classe. A renúncia à singularidade étnica ou cultural foi explícita, embora sua afirmação seja cada vez menos desqualificadora. Ocorreu formação de classes, mas não formação racial. De qualquer modo, nos dias de hoje, generaliza-se entre as esquerdas, ao menos, a ideia de que o povo brasileiro é negro ou mestiço.

O período que se vive é o primeiro em que se recusa os pressupostos autoritários da democracia racial, que buscava a harmonia sem consolidar a ordem política e equalizar a distribuição social das riquezas e das oportunidades. O protagonismo maior agora passa a ser dos movimentos sociais, ainda que o Estado se mantenha central, como distribuidor e doador. É nessa ordem de garantia dos direitos individuais e coletivos que medram o reconhecimento da singularidade étnica e o respeito à igualdade racial. De modo apenas aparentemente paradoxal, a afirmação do coletivo racial serve para aprofundar a igualdade entre os cidadãos. A razão parece estar em que as desigualdades precisam agora ganhar nome (cor, gênero, raça, orientação sexual) para serem combatidas. 


\section{Antonio Sérgio Alfredo Guimarães \\ é professor do Departamento de Sociologia da USP.}

\section{Referências bibliográficas}

ABREU, M.; DANTAS, C. 2011. "É chegada 'a ocasião da negrada bumbar': comemorações da abolição, música e política na Primeira República”. (mimeo.).

ALBUQUERQUE, W. R. 2009. O jogo da dissimulação: abolição e cidadania negra no Brasil. São Paulo: Companhia das Letras.

ALONSO, A. 2010. "A teatralização da política: a propaganda abolicionista”. Texto apresentado ao seminário Sociologia, História e Política do PPGS-USP. São Paulo: (mimeo.).

ARAÚJO, R. B. 1995. Guerra e paz: Casa-grande $\xi^{\circ}$ senzala e a obra de Gilberto Freyre nos anos 30. Rio de Janeiro: Ed. 34.

AZEVEDO, T. 1963. "Race and class". In: Social change in Brazil. Gainesville: University of Florida Press, pp. 32-56.

BARBOSA, M. 1998. Frente Negra Brasileira: depoimentos. São Paulo: Quilombhoje.

BASTIDE, R. 1976. "Négritude et intégration nationale: la classe moyenne de couleur devant les religions afro-brésiliennes”. Afro-Ásia, no 12, pp. 17-30.

BASTIDE, R. 1961. "Variations on negritude". Presence Africaine, vol. 8, no 36, pp. 83-92.

BASTIDE, R. 1983. "A imprensa negra do Estado de São Paulo”. In: Estudos afro-brasileiros. São Paulo: Perspectiva.

BOURDIEU, P. 1979. La distinction: critique sociale du jugement. Paris: Minuit.

CAMPOS, M. J. 2005-2006. "Cassiano Ricardo e o mito da democracia racial”. Revista USP, no 68, pp. 140-155.

CARVALHO, J. M. 1987. Os bestializados: o Rio de Janeiro e a República que não foi. São Paulo: Companhia das Letras.

2002. Cidadania no Brasil: o longo caminho. Rio de Janeiro: Civilização Brasileira.

COSTA, E. V. 1985. The Brazilian empire. Chicago: University of Chicago Press.

CUNHA, E. 1902. Os sertões. Rio de Janeiro: Laemmert.

DAMATTA, R. 1990. "Digressão: a fábula das três raças, ou o problema do racismo à brasileira”. In: Relativizando: uma introdução à antropologia social. Rio de Janeiro: Rocco, pp. 58-87.

DANTAS, C. V. 2010. "Monteiro Lopes (1867-1910), um 'líder da raça negra' na capital da República”, Afro-Ásia, vol. 41, pp.167-209.

DIAZ QUIÑNONES, A. 2006. Sobre los principios: los intelectuales caribeños y la tradición. Quílmes: Universidad Nacional de Quílmes. 
DUARTE, P. 1947. “O negro no Brasil”. O Estado de São Paulo, pp. 5-6.

DUMONT, L. 1960. “Castes, racisme et stratitification”. Cahiers Internationaux de Sociologie, vol. 29, pp. 91-112.

FERNANDES, F. 1965. A integração do negro na sociedade de classes. São Paulo: Dominus.

FERRARA, M. N. 1986. A imprensa negra paulista (1915-1963). São Paulo: FFLCH-USP.

FREYRE, G. 1933. Casa-grande Ev senzala. Rio de Janeiro: Schmidt.

FREYRE, G. 1936. Sobrados e mucambos. Rio de Janeiro: Ed. Nacional.

GARCIA, A. 1986. "Libres et assujettis". Actes de la Recherche en Sciences Sociales, vol. 65 , pp. 14-40.

GOMES, A. C. 1999. História e historiadores. Rio de Janeiro: Ed. FGV.

2001. "Gilberto Freyre e Oliveira Lima: Casa-grande e senzala e o contexto historiográfico do início do século XX”. História, vol. 20, pp. 29-44.

GOMES, F. 1999. "No meio das águas turvas. Racismo e cidadania no alvorecer da República: a Guarda Negra na Corte - 1888-1889”. Estudos Afro-Asiáticos, no 21, pp. 74-95.

GUERREIRO RAMOS, A. 1957. Introdução crítica à sociologia brasileira. Rio de Janeiro: Andes.

GUIMARÃES, A. S. A. 1999. Racismo e antirracismo no Brasil. São Paulo: Ed. 34. 2001. "Democracia racial: o ideal, o pacto e o mito". Novos Estudos Cebrap, vol. XX, no 61, pp. 147-162. 2002. Classes, raças e democracia. São Paulo: Ed. 34.

2011. "A República de 1889: utopia de branco, medo de preto (A liberdade é negra; a igualdade, branca e a fraternidade, mestiça)". Contemporânea, no 2 , pp. 17-36.

; MACEDO, M. J. 2008. "Diário trabalhista e democracia racial negra dos anos 1940”. Dados, vol. 51, pp. 143-182.

HARRIS, M. Town and country in Brazil. Nova York: Columbia University Press, 1956.

HERSKOVITS, M. 1943. "The negro in Bahia, Brazil: a problem of method". American Sociological Review, vol. 8, pp. 394-402.

JESUS, M. G. 2010. Negro, porém republicano: investigações sobre a trajetória intelectual de Raul Astolfo Marques (1876-1918). Dissertação de Mestrado em Sociologia. São Paulo: FFLCH-USP.

LACERDA, J. B. 1911. Sur les métis au Brésil. Paris: Imprimerie Devouge.

LEITE, J. C. 1992. ...E disse o velho militante José Correia Leite. São Paulo: Secretaria Municipal de Cultura.

OLIVEIRA LIMA, M. 1911. Formation historique de la nationalité brésilienne. Paris: Ed. Garnier. 
1922. O movimento da Independência. São Paulo: Companhia Melhoramentos.

LIMA, V. C. 1964. "Ainda sobre a Roma negra”. Diário de Notícias, 12 jan.

MARSHALL, T. H. [1963] 1977. Class, citizenship, and social development: essays. Chicago/Londres: University of Chicago Press.

MNU. 1982. "Programa de ação". Texto aprovado no III Congresso do MNU. Belo Horizonte (mimeo.).

NASCIMENTO, Abdias. 1968. "Depoimento”. Cadernos Brasileiros, no 47. 1978. O genocídio do negro brasileiro. Rio de Janeiro: Paz e Terra.

NASCIMENTO, J.; GAMA, H. (orgs.). 2009. Manoel Querino: seus artigos na revista do IGHB. Salvador: IGHB.

RAMOS, A. 1937. As culturas negras no Novo Mundo. Rio de Janeiro: Civilização Brasileira.

ROBESON, P.; PATTERSON, W. 1970. We charge genocide: the historic petition to the United Nations for relief from a crime of the United States government against the negro people. Nova York: Civil Rights Congress/International Publishers.

SANTOS, J. T. 2005. O poder da cultura e a cultura do poder. Salvador: Edufba. SANTOS, W. G. 1979. Cidadania e justiça. Rio de Janeiro: Campus.

40 das Letras.

SEVCENKO, N. 1998. "Introdução: o prelúdio republicano, astúcias da ordem e ilusões do progresso”. In: História da vida privada no Brasil. São Paulo: Companhia das Letras (vol. 3). . [1985] 2010. A Revolta da Vacina. São Paulo: Cosac Naify.

SKIDMORE, T. 1974. Black into white: race and nationality in Brazilian thought. Durham: Duke University Press.

TROCHIM, M. R. 1988. "The Brazilian black guard: racial conflict in post-abolition Brazil”. The Americas, vol. 44, no 3, pp. 285-300.

TURNER, B. 1990. "Outline of a theory of citizenship". Sociology, vol. 24, pp. 189-217.

VENTURA, R. 1991. Estilo tropical: história cultural e polêmicas literárias no Brasil (1870-1914). São Paulo: Companhia das Letras.

OLIVEIRA VIANNA, F. J. 1959. Raça e assimilação. Rio de Janeiro: José Olympio. VIANNA, L. W.; CARVALHO, M. A. R. "República e civilização brasileira", Estudos de Sociologia, n. 8, 2000, pp. 7-33.

VON MARTIUS, K. F. [1845] 1956. "Como se deve escrever a História do Brasil”. Revista de Historia de América, no 42, pp. 433-458.

WEFFORT, F. 1992. Qual democracia? São Paulo: Companhia das Letras. 


\section{CIDADANIA E RETÓRICAS NEGRAS DE INCLUSÃO SOCIAL}

\section{ANTONIO SERGIO ALFREDO GUIMARÃES}

Resumo: A formação das classes sociais brasileiras de certo modo coincidiu com as hierarquias herdadas da colonização: os povos anteriormente conquistados ou escravizados, que passaram a ser definidos por meio da classificação por raças, nesse processo tornaram-se também subalternos. A extensão de direitos iguais para todos os membros da nação se constituiu igualmente de forma peculiar. Neste artigo, eu exploro o modo pelo qual as hierarquias sociais se mantiveram e se reproduziram no contexto em que a liberdade individual foi a base para a formação nacional, assim como a maneira com que os anseios históricos de liberdade cederam lugar, na motivação dos ativistas negros, à igualdade de oportunidades.

Palavras-chave: Cidadania; Ativismo negro; Retórica de mobilização; Inclusão social.

\section{CITIZENSHIP AND BLACK RHETORIC FOR SOCIAL INCLUSION}

Abstract: The formation of Brazilian social classes coincided somehow with hierarchies inhered from colonization: the peoples previously conquered and enslaved, who became defined through the classification by race, in that process also became subordinate. The extention of equal rights among the nation's members was constituted in a particular way. In this article I explore how social hierarchies were maintained and reproduced in an ideological context in which the liberty of citizens was the basis for the formation of the modern nation, and how the historical claim for freedom was substituted by equality as political motivation for Black activism.

Keywords: Citizenship; Black activism; Mobilization rhetoric; Social inclusion.

Recebido: 25/07/2011 Aprovado: 03/10/2011 